\title{
Compromiso ético, independencia intelectual y ayuda en momentos de crisis. España (1914-1939) ${ }^{1}$
}

\author{
ESPERANZA GUILLÉN
}

\begin{abstract}
Ethical Commitment, Intellectual Independence and Help in Times of Crisis. Spain (1914-1939). This article examines the relation between some Spanish intellectuals prominent in fields such as literature, philosophy, music or visual arts. The text analyzes how those bonds of friendship conditioned their professional careers and even their life in difficult times. In order to do that, I will follow the trajectory of Luis Bagaría, a caricaturist connected with almost all the protagonists of this article, which focuses, among other things, on the ideological independence of Miguel de Unamuno. The friendship of Manuel de Falla and Manuel Ángeles Ortiz, Federico García Lorca and Hermenegildo Lanz will also be examined. The text will also pay attention to how the musician intervened in order to prevent the killing of Lanz in Granada, something that did not work in the case of García Lorca. Moreover, I will develop the topic on the help of Picasso to many artists (among them Ángeles Ortiz) running away of the Spanish Civil War. Above all, this text will focus on the intellectual freedom and the ethical commitment of those, like Unamono and Falla, who were placed at a difficult position among the two sides confronted in this war.
\end{abstract}

Keywords: Luis Bagaría; Falla; Miguel Unamuno; Federico García Lorca; Manuel Ángeles Ortiz; Pablo Picasso; Hermenegildo Lanz

Tras una larga agonía, el escultor Julio Antonio murió el 15 de febrero de 1919. Francisco Pompey describe así sus últimos momentos:

No podía articular palabra alguna, pero sí mostrar su boca, abierta y abrasada por una sed mortal; fue Bagaría el que acercaba su boca con saliva y se la ofrecía a Julio Antonio, para calmar su angustia de muerte. Nunca olvidaré aquella escena: Julio Antonio, ya muerto en la cama; su madre sollozando sobre el rostro de su hijo; y en torno al amigo sin vida, Bagaría, Jesús Lozano, el escultor,

1 Este texto recoge parte de los resultados del proyecto de investigación HAR201231321. El artista y el dolor. El sufrimiento como límite de la representación en la cultura artística contemporánea, financiado por el Ministerio de Economía y Competitividad de España.

DOI: https://doi.org/10.12697/IL.2017.22.1.13 
y el que esto escribe. Al final de la mañana, Daniel Vázquez Díaz hizo un dibujo de la cabeza de Julio Antonio. (Pompey 1972: 60)

Julio Antonio falleció con solo 30 años, pero hasta entonces fue considerado por un sector de la crítica española como el más excelente escultor de su época. He querido comenzar con esta escena protagonizada por uno de los mejores amigos del fallecido mojando con su propia saliva los labios ardientes de sed de Julio Antonio para poner de relieve la profunda humanidad del caricaturista Luis Bagaría, que de algún modo va a ser el hilo conductor de este texto sobre la libertad intelectual y sobre las relaciones de amistad que se ponen en evidencia en los peores momentos, en los momentos en los que, realmente, se precisa la ayuda.

Los apoyos generados en el seno del sistema de las artes son muchas veces los que garantizan el éxito o, cuando menos, la supervivencia. Voy a centrarme en el amparo que por diversas razones algunos intelectuales españoles, procedentes de diferentes ámbitos, se prestaron entre sí en momentos difíciles. Estos apoyos fueron desde la ayuda económica o la asistencia durante la enfermedad o durante los últimos momentos de la vida -como hemos señalado en el caso de Julio Antonio-, a servicios como escribir una crítica para favorecer la venta de cuadros. Pero también hablaré de cómo la intervención de ciertos intelectuales españoles contribuyó a que los amigos presos alcanzaran la libertad.

Luis Bagaría fue posiblemente el mejor caricaturista de la prensa gráfica española de la primera mitad del siglo $\mathrm{XX},{ }^{2}$ gracias a la cual desarrolló una ácida crítica política y social. Barcelonés de nacimiento, tras unos años en la ciudad mejicana de Puebla, adonde se trasladó la familia tras el fallecimiento de su padre, regresó a Barcelona en 1902, frecuentando los círculos intelectuales más activos del modernismo como la taberna de Els Quatre Gats, que entre otras actividades celebraba exposiciones (las dos primeras individuales que Picasso realizó en su vida tuvieron lugar allí en febrero y julio de 1900), veladas literarias y musicales o espectáculos de diversa naturaleza y donde Bagaría se relacionó con Ramón Casas, Isidre Nonell, Santiago Rusiñol y es posible que con un joven Pablo Picasso que ya repartía su tiempo entre Barcelona y París, donde el pintor se instaló de manera definitiva en 1904.

Bagaría empieza a hacer en Barcelona caricaturas para La Tribuna, actividad que retomarás tras pasar 1908 en la Habana colaborando con El Diario Español y el semanario Fígaro. Aunque piensa en la posibilidad de marcharse a París para dedicarse a la pintura (como hará Juan Gris, que también comenzó a ganarse la

2 Sobre Luis Bagaría ver Elorza 1988, Marcos Villalón 2004 , A.A.V.V. 2007, Esteban 2009. 
vida como ilustrador gráfico y caricaturista), cuando en 1912 La Tribuna abra una sucursal en Madrid, animado por Santiago Rusiñol, Bagaría se traslada a la capital española. Durante la Primera Guerra Mundial, cuando José Ortega y Gasset fundó la revista España, de carácter liberal y en apoyo a los aliados, el caricaturista comenzó a diseñar muchas de sus portadas, y lo seguirá haciendo hasta 1942, actividad que compartió con sus dibujos para el diario El Sol. Declarado antibelicista, sus viñetas y dibujos de la Guerra de 1914 demuestran su abierto rechazo a la violencia.

Luis Bagaría se afilió al PSOE en 1920, y durante la dictadura del general Miguel Primo de Rivera sufrió duramente la censura que le obligó, incluso, a marchar a Buenos Aires en 1925 y hasta 1927. Más tarde seguiría siendo perseguido por los censores y alejado de su trabajo para El Sol entre 1931 y 1934, es decir, en plena República. A lo largo de su vida debió afrontar innumerables multas, la prohibición de sus viñetas, incontables procesos y algunas penas de cárcel, por las mordaces sátiras a políticos y burgueses, al clero o al ejército que hizo este "dibujante salvaje", como le gustaba autodefinirse, inteligente y profundamente humano y con un hondo sentido de la conciencia social.

A pesar de su claro anticlericalismo, Bagaría tuvo una estrecha relación con Miguel de Unamuno, un hombre de profundas convicciones religiosas a quien representó en múltiples ocasiones. Sabemos que Unamuno prestó constante apoyo a los artistas, especialmente a aquellos que no gozaban de los aplausos del sistema académico, como Zuloaga o Regoyos. ${ }^{3}$ Entre ellos se encontraba Luis Bagaría. En 1916, Ricardo Gutiérrez Abascal (el crítico que firmaba con el pseudónimo de Juan de la Encina) ejercerá de intermediario para conseguir del escritor unas líneas acerca de la actividad de Bagaría como caricaturista:

Quiere este hacer una exposición de sus caricaturas en Bilbao, y le gustaría que en el catálogo de las obras que ha de exponer figuraran algunos juicios breves de los escritores y artistas más distinguidos de España sobre su obra. Naturalmente, quiere que su juicio de Vd. figure en ese catálogo, y como él no es hombre muy dado a manejar la pluma, aunque es catalán, me encarga le haga a Vd. la petición de un par de líneas. (González de Durana 1986: 249). ${ }^{4}$

Y es que conseguir exponer la obra en público, en una galería o en alguna institución, para hacerse un hueco en el campo artístico, es siempre difícil, sobre todo cuando se accede por primera vez a un mercado imprevisible, a no ser que

Sobre la relación de los artistas españoles con el sistema de las artes ver Guillén 2013.

4 Carta de Ricardo Gutiérrez Abascal a Miguel de Unamuno, 27 de enero de 1916. 
se cuente de antemano con los avales suficientes, cifrados especialmente en las críticas que publica la prensa.

Unamuno, que sería rector de la Universidad de Salamanca en tres ocasiones, fue nombrado por primera vez en 1900 con solo 36 años. ${ }^{5}$ En 1914 fue cesado por razones políticas. Seis años después, en 1920, cuando era decano de la Facultad de Filosofía y Letras, acusado de injurias a Alfonso XIII fue condenado a dieciséis años de cárcel, aunque no se ejecutó la sentencia y siguió expresando públicamente sus opiniones sobre el Rey. La distancia que separa a muchos intelectuales liberales del poder conservador y de la monarquía era cada vez mayor. De ideas socialistas, Unamuno era un ferviente defensor de la tradición cultural española, pero enemigo de la cerrazón mental de los sectores más conservadores; era una persona con arraigadas convicciones políticas pero que rechazaba formar parte de ningún partido porque para él "todo partido político es dogmático":

Un pensador político no puede ser nunca un hombre de partido, a menos de renunciar a pensar. Porque los hombres de partido político no piensan políticamente. Son, a lo sumo, abogados del pensamiento, pero no legisladores de él. Aplican dogmas, pero son incapaces de crear ideas" (Ouimette 1982: 28)

El largo conflicto con Marruecos no contribuía a mejorar la situación. Cuando en septiembre de 1923 el general Miguel Primo de Rivera dé un golpe de Estado, se romperá la legalidad parlamentaria. El golpe fue anunciado por un manifiesto en el que se aludía a la masculinidad como salvadora de la patria española. Unamuno calificó el manifiesto como "pornográfico”. La situación en España era muy complicada. Los republicanos radicales de Lerroux se mostraron débiles, en Partido Socialista Obrero Español y el sindicato U.G.T. se mantuvieron neutrales con la Dictadura y muchos intelectuales de izquierdas como Unamuno comenzaron a escribir contra Primo de Rivera. Para él, no eran la bravuconería y la masculinidad las que salvarían al país, sino la inteligencia y la razón. Tampoco entonces se afilió a ninguno de los partidos o grupos que se organizaban frente a la dictadura porque, como escribe en El Liberal:

Nuestro magisterio no es, no puede ser dogmático; tiene que ser crítico. Dictar normas es engañar al prójimo. Dictar normas es matar la libertad de inteligencia, porque la inteligencia es libertad... Entender es lo único que

5 La bibliografía sobre Miguel de Unamuno es extensísima. Para analizar su vida y su obra recomendamos Gómez Molleda 2002, Urrutia 1997, Urrutia Jordana 2015.

6 Nuevo Mundo, 12 de mayo de 1922. 
liberta. La obediencia ciega, propia del esclavo, no es de hombres. ${ }^{7}$ (Urrutia 2015: 53-54)

La inteligencia debía ser crítica. Sometido a la censura de muchos de sus textos en España, siguió publicando desde Francia o Argentina. Por citar un ejemplo, en Le Quotidien Unamuno calificó de ignominia el manifiesto golpista de Primo de Rivera: "Esta pobre España, hoy víctima de la reacción más bárbara. Una

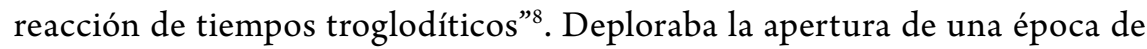
persecución de la inteligencia y de denuncias secretas. Como consecuencia de todo esto, en 1924, por orden del Directorio militar que presidían Miguel Primo de Rivera y Severiano Martínez Anido, fue desterrado a la isla canaria de Fuerteventura. Cuando se hizo pública la orden de destierro, Martínez Anido, según parece, exclamó: "Yo cortaría varias cabezas de "intelectuales" para que no molesten más. Si yo pudiera realizar mi programa, Unamuno no llegaría vivo a Fuerteventura. ¡A mí me tienen sin cuidado los intelectuales!”9 (Ouimette 1982: 35)

El filósofo aceptó el destierro, pero se produjo una reacción creciente de indignación y protestas tanto en España como en muchos países europeos e hispanoamericanos que pedían que se levantara un castigo tan injusto. La presión internacional consiguió que fuera indultado a los seis meses. No obstante, no dispuesto a seguir sufriendo los acosos de la censura, el filósofo optó por el destierro voluntario a Francia, donde permaneció hasta la caída de Primo de Rivera en 1930.

Unamuno resultó luego elegido concejal por el grupo socialista republicano en las elecciones del 12 de abril de 1931 y proclamó la República en Salamanca. Desde el balcón municipal exhortó a sus conciudadanos afirmando el comienzo de una nueva era y el final de una dinastía "que nos ha empobrecido, envilecido y entontecido”. Fue nombrado de nuevo rector y elegido diputado en cortes. La victoria del Frente Popular en las elecciones de febrero de 1936 agudizó las movilizaciones populares. Se sucedieron las huelgas y los destrozos públicos. El descontento con la política agraria, con la deriva antirreligiosa creciente que provocaba la quema de iglesias y la destrucción del patrimonio artístico, el cariz violento que estaban tomando los acontecimientos y ciertas actitudes de los dirigentes y especialmente del presidente de gobierno, Manuel Azaña, llevaron a Unamuno a alejarse de la política, aunque fue nombrado rector vitalicio.

\footnotetext{
El Liberal, 3 de octubre de 1923.

$8 \quad$ Le Quotidien (Paris), 29 de diciembre de 1923.

9 La frase de Anido fue dicha a Gregorio Marañón y Luis de Tapia (Ortega y Gasset 1925: 258).
} 
Cuando estalló la Guerra Civil, pese a haber simpatizado siempre con las ideas socialistas y haber sido un gran defensor de las libertades y de la República, Unamuno apoyó sin embargo a los militares rebeldes encabezados por Francisco Franco, considerando que solo ellos serían capaces de restaurar el orden en España, cuya cultura y tradición cristianas estaba en peligro. De hecho, aceptó incluso ser concejal y, para sorpresa y rechazo de muchos intelectuales europeos, hizo en 1936 un llamamiento de apoyo a las fuerzas militares sublevadas. El presidente de la República, Azaña, lo destituyó, pero el gobierno franquista de Burgos volvió a nombrarlo rector vitalicio.

Lo que le había parecido ser la única solución a los males del país pronto se tornó para él en una pesadilla ante los abusos de autoridad del bando de los nacionales que dieron lugar a torturas y ejecuciones. Su discípulo Salvador Vila Hernández, rector de la Universidad de Granada, fue ejecutado, así como su también amigo el alcalde republicano de Salamanca, Casto Prieto Carrasco. Unamuno llegó a visitar a Franco para rogarle clemencia en un intento por evitar fusilamientos de sus amigos, lo que tampoco consiguió en el caso de Atilano Coco, masón y pastor anglicano.

Una conocida anécdota da cuenta de la libertad de espíritu del filósofo. La anécdota sitúa a nuestro protagonista en el paraninfo de la Universidad de Salamanca el 12 de octubre de 1936 durante el acto solemne de apertura del curso académico. Salamanca estaba en poder de las tropas del general Franco y la ceremonia serviría para pulsar la adhesión de los concurrentes al patriotismo y a la religiosidad enarboladas por los nacionales franquistas. Miguel de Unamuno presidía el acto. Las intervenciones de José María Ramos Loscertales y del fraile dominico Vicente Beltrán de Heredia supusieron un enaltecimiento del Imperio y los valores de la raza (un concepto muy en boga y esencial para comprender el espíritu que animara no solo a los sectores más conservadores, sino en general al regeneracionismo liberal desde finales del siglo XIX). El siguiente en intervenir fue Francisco Maldonado de Guevara, catedrático de literatura, declarado derechista y que había sido rector de la misma universidad. Su discurso fue una declarada crítica al antiespañolismo de vascos y catalanes, a quienes consideraba un cáncer para la salud nacional que había que extirpar. José María Pemán intervino después para enardecer el ánimo del auditorio refiriéndose a la conocida resistencia del Alcázar de Toledo. El momento fue aprovechado por el general Millán-Astray para concitar el entusiasmo de sus seguidores con un "España, Grande y Libre” que concluyó con el saludo de algunos falangistas, brazo en alto, al retrato del general Franco. Aunque lo que ocurrió a continuación no está bien contrastado, porque hay versiones diferentes, Miguel de Unamuno hizo uso de la palabra para pronunciar 
GUILLÉN

un discurso que sería así recogido por Luis Gabriel Portillo en 1941 y más tarde difundido por el hispanista Hugh Thomas:

\begin{abstract}
Estáis esperando mis palabras. Me conocéis bien, y sabéis que soy incapaz de permanecer en silencio. A veces, quedarse callado equivale a mentir, porque el silencio puede ser interpretado como aquiescencia. Quiero hacer algunos comentarios al discurso - por llamarlo de algún modo- del profesor Maldonado, que se encuentra entre nosotros. Se ha hablado aquí de guerra internacional en defensa de la religión cristiana; yo mismo lo hice otras veces. Pero no, la nuestra es solo una guerra incivil. Vencer no es convencer, y hay que convencer, sobre todo, y no puede convencer el odio que no deja lugar a la compasión. Dejaré de lado la ofensa personal que supone su repentina explosión contra vascos y catalanes llamándolos anti-España; pues bien, con la misma razón pueden ellos decir lo mismo. El señor obispo lo quiera o no lo quiera, es catalán, nacido en Barcelona, y aquí está para enseñar la doctrina cristiana que no queréis conocer. Yo mismo, como sabéis, nací en Bilbao y llevo toda mi vida enseñando la lengua española, que no sabéis... (Thomas 1961: 294)
\end{abstract}

Según ese relato, el general Millán Astray empezó a pedir a gritos la palabra, mientras alguna persona gritaba el lema de la legión española: “iViva la muerte!”. Millán, tremendamente excitado, secundó el discurso de Maldonado y dijo: “¡Cataluña y el País Vasco, el País Vasco y Cataluña, son dos cánceres en el cuerpo de la nación! El fascismo, remedio de España, viene a exterminarlos, cortando en la carne viva y sana como un frío bisturí!”. En su réplica, Unamuno llamó a Millán símbolo de la muerte y replicó:

El general Millán-Astray es un inválido. No es preciso que digamos esto con un tono más bajo. Es un inválido de guerra. También lo fue Cervantes. Pero los extremos no sirven como norma. Desgraciadamente en España hay actualmente demasiados mutilados. Y, si Dios no nos ayuda, pronto habrá muchísimos más. Me atormenta el pensar que el general Millán-Astray pudiera dictar las normas de la psicología de las masas. Un mutilado que carezca de la grandeza espiritual de Cervantes, que era un hombre, no un superhombre, viril y completo a pesar de sus mutilaciones, un inválido, como he dicho, que no tenga esta superioridad de espíritu es de esperar que encuentre un terrible alivio viendo cómo se multiplican los mutilados a su alrededor. El general Millán-Astray desea crear una España nueva, creación negativa sin duda, según su propia imagen. Y por eso quisiera una España mutilada. (Thomas 1961: 294) 
Compromiso ético, independencia intelectual y ayuda en momentos de crisis

A pesar de los gritos contra la intelectualidad traidora que se oyeron en la sala, Unamuno, sin amedrentarse, continuó:

Venceréis, porque tenéis sobrada fuerza bruta. Pero no convenceréis, porque para convencer hay que persuadir. Y para persuadir necesitaréis algo que os falta: razón y derecho en la lucha. Me parece inútil el pediros que penséis en España. (Thomas 1961: 295)

Ese mismo día, el ayuntamiento de Salamanca lo expulsó como concejal y el 22 de octubre Franco firmó el decreto de destitución como rector de esa universidad. Se ordenó su arresto domiciliario. Murió el 31 de diciembre de 1936. Cuando ya estaba recluido en su casa, Unamuno había declarado pocos días antes en una entrevista concedida a Kazantzaquis:

No preste atención a lo que se dice de mí: no me he convertido en un hombre de derechas, no he traicionado a la libertad. Pero de inmediato es urgente instaurar el orden. Verá cómo dentro de algún tiempo y esto no será dentro de mucho, seré el primero en reemprender la lucha por la libertad. No soy fascista ni bolchevique. Soy solamente un solitario. (Urrutia 1997: 306)

Retrocedamos en el tiempo. Bagaría había realizado caricaturas de Manuel de Falla en 1915 con motivo del estreno en Madrid de El amor Brujo. En París, donde vivió diez años, el compositor había conocido al matrimonio formado por Gregorio Martínez Sierra y su mujer, la auténtica autora del texto, María Lejárraga, quienes habían alquilado el Teatro Lara para un espectáculo de "gitanería" que debía protagonizar Pastora Imperio. Años después, en Granada, encontraremos de nuevo a Bagaría asociado al nombre de Falla realizando ilustraciones sobre el Festival de Cante Jondo de 1922, el primero de esta naturaleza celebrado en España y para el que Ignacio Zuloaga hizo los telones y Hermenegildo Lanz los carteles. El festival fue una iniciativa de Miguel Cerón que contó con el entusiasta apoyo de Falla y de Federico García Lorca. Es célebre la fiesta, que prepararon ambos el día 6 de enero de 1923, dedicada a las niñas de la familia Lorca (Isabel García Lorca y Laura, hija de Fernando de los Ríos). Con Falla al piano, se representó un auto sacramental del siglo XIII, El Auto de los Reyes Magos. Asimismo, García Lorca adaptó para títeres un cuento popular La niña que riega la albahaca y el príncipe preguntón. Las marionetas fueron realizadas por Hermenegildo Lanz, que fue junto a Lorca uno de los fundadores de la tertulia del Rinconcillo, que se reunía en el café Alameda de Granada y cuyos tertulianos impulsaron una renovación del arte y la literatura 
española en conexión con preocupaciones intelectuales de las vanguardias europeas sin perder el sentido de lo vernáculo. Tanto le gustaron a Falla las marionetas de Lanz que le encargó títeres y figuras planas para la representación el París de El retablo de Maese Pedro, estrenado en la residencia parisina de la princesa Edmond de Polignac en julio de ese año. Para los decorados y los figurines contaron, además, con la colaboración de Manuel Ángeles Ortíz.

Cuando comenzaron los ataques a iglesias y a los religiosos, Falla encabezó, junto a otras firmas como la de Lanz, un telegrama dirigido al presidente de la República, Niceto Alcalá Zamora, el 14 de mayo de 1931:

Grupos no numerosos han estado dos días cometiendo en la ciudad toda clase de sacrilegios, atropellos a domicilios religiosos e insultos a sus personas, sin eficaz intervención autoridades. A V. Respetuosamente, como representante supremo Poder, acudimos con nuestra información y nuestra indignada protesta. $^{10}$

Cuando en febrero de 1936 triunfó en Granada la candidatura de derechas hubo una movilización que condujo a la anulación de las elecciones y a que se acordara una segunda vuelta, pero los disturbios en la ciudad tuvieron desastrosas consecuencias como el saqueo y los incendios del teatro Isabel la Católica, de comercios, cafés y fábricas, de los talleres del periódico Ideal, o de las iglesias de El Salvador, San Cristóbal, San Gregorio el Bajo y el convento de San Gregorio el Alto. Falla escribió a Manuel Azaña, ahora presidente de la República, solicitando en junio de ese terrible año su intervención para evitar la destrucción de templos. Ese mismo mes Luis Bagaría realizó la última entrevista a Federico García Lorca.

- L.B.: ¿No crees Federico, que la patria no es nada, que las fronteras están llamadas a desaparecer? ¿Por qué un español malo tiene que ser más hermano nuestro que un chino bueno?

- G. L.: Yo soy español integral, y me sería imposible vivir fuera de mis límites geográficos; odio al que es español por ser español nada más. Yo soy hermano de todos y execro al hombre que se sacrifica por una idea nacionalista abstracta por el solo hecho de que ama a su patria con una venda en los ojos. El chino bueno está más cerca de mí que el español malo. Canto a España y la

10 AMF, carpeta 6.788. Encabeza las firmas Manuel de Falla y le siguen Ramón Pérez Roda, Francisco González Méndez, José María Bérriz, Eusebio Borrajo, José Segura, Emilio García Gómez y Hermenegildo Lanz. (Titos 2011: 214) 
Compromiso ético, independencia intelectual y ayuda en momentos de crisis

siento hasta la médula; pero antes que esto soy hombre de mundo y hermano de todos. Desde luego, no creo en la frontera política.

- L.B.: ¿Crees tú que al engendrar la poesía se produce un acercamiento hacia un futuro más allá, o al contrario, hace que se alejen más los sueños de otra vida?

- G.L.: [...] creo firmemente que si hay un más allá tendré la agradable sorpresa de encontrarme con él. Pero el dolor del hombre y la injusticia constante que mana del mundo, y mi propio cuerpo y mi propio pensamiento, me evitan trasladar mi casa a las estrellas. (Bagaría 1936)

Un mes más tarde, el 18 de julio, estalló la Guerra Civil, y el ejército sublevado bajo las órdenes de Franco se hizo con la ciudad de Granada. Comenzaron las represalias. En agosto de 1936, Federico García Lorca fue fusilado. Manuel de Falla, que no pudo hacer nada para evitar su muerte, temió por la seguridad de Hermegildo Lanz y remitió una carta al capitán José María Nestares el 3 de septiembre de ese año:

Aun sin tener el gusto de conocerle personalmente, me permito dirigirme a Vd. para rogarle su ayuda, que creo eficacísima, en asunto que vivamente me preocupa, esperando que, por la posible gravedad del mismo, perdonará Vd. mi atrevimiento y las molestias que por ello le cause. Se trata de don Hermegildo Lanz, antiguo y muy querido amigo nuestro, y hasta colaborador artístico en una de mis obras en la que realizó el decorado.

Como quizá sepa Vd., dicho Sr. fue detenido y puesto en libertad. Ahora me dicen que vuelve a estar en peligro, y hasta tal vez, con graves consecuencias. Muy angustiado por ello, y sabiendo que Vd. también es amigo suyo, confío en que compartirá mis sentimientos, rogándole me indique qué pudiera yo hacer, ya sea en unión de Vd., o en la forma que Vd. crea más oportuna, para ayudar en este trance a nuestro amigo. (Quesada 2001: 150)

Manuel de Falla logró que el artista no fuera ajusticiado. Diez años después de finalizada la Guerra Civil, Hermenegildo Lanz murió en la calle cuando salía de un curso de reeducación y adoctrinamiento político-religioso. ${ }^{11}$ El propio Falla hubo de rellenar un cuestionario de depuración para el que eran precisos los avales de dos personas afectas al régimen franquista.

Creo necesario dejar claras algunas cosas: Miguel de Unamuno, como Manuel de Falla, eran convencidos liberales y por eso no traicionaron sus ideales cuando criticaron las violentas derivas de la República. Unamuno, como Falla, eran hombres religiosos y cultos que denunciaron el pillaje y la destrucción

11 Sobre la vida y la obra de Lanz, ver Mata Anaya 2004. 
de iglesias y la consiguiente pérdida irremediable de magníficas obras de arte a manos de grupos radicales de izquierdas. Esa no era su idea de socialismo, ni de comunismo. Los vándalos no eran socialistas sino salvajes. Tampoco traicionaron sus ideales cuando se acercaron e incluso apoyaron al bando sublevado e intentaron salvar la vida de personas como el rector de Granada, Salvador Vila Hernández, Federico García Lorca o Hermengildo Lanz. Eran convencidos liberales que consideraron en algún momento que era preciso restablecer el orden, aunque fuera mediante el ejército. Pero del mismo modo que acusaron los desmanes de algunos republicanos, también denunciaron la represión sinsentido de las tropas nacionales franquistas, lo que condujo de nuevo a Unamuno a la pérdida del rectorado y al arresto domiciliario hasta su muerte, y a Falla lo sumió en una profunda tristeza, que unida a su frágil situación económica y al inicio de la Segunda Guerra Mundial determinaron su marcha a Argentina en septiembre de 1939. Desde allí, siguió intercediendo por sus amigos.

La historia no puede ser pintada en blanco o negro. Como ejemplo, baste el siguiente: Un íntimo amigo de Federico García Lorca, Joaquín Amigo, -uno de los creadores de uno de los más sobresalientes testimonios de la modernidad vanguardista en España, la revista Gallo, donde se publicó el Manifiesto Amarillo- profesor de filosofía en un instituto al comienzo de la Guerra Civil, fue arrojado por el puente de la localidad malagueña de Ronda por soldados republicanos. Dos compañeros, dos grandes intelectuales, Federico García Lorca y Joaquín Amigo, fueron asesinados por los dos bandos contendientes. ${ }^{12}$ Las consecuencias de esta guerra son sobradamente conocidas. Francisco Franco impuso durante cuarenta años una dictadura, y la libertad se vio condicionada por la censura.

Pero retornemos en el tiempo una vez más. A Manuel Ángeles Ortiz lo hemos mencionado ya cuando estaba en Granada en compañía de Federico García Lorca, padrino de su hija Isabel Clara, y de Manuel de Falla. A la muerte de la mujer del pintor, en 1922 Falla le recomendó que se marchase a París y le entregó una carta dirigida a Pablo Picasso, con quien había colaborado en El sombrero de tres picos que se presentó primero en Londres y luego en París. Eduardo Quesada Dorador recoge en Manuel de Falla en Granada la carta de presentación que el compositor escribe a Picasso el 28 de septiembre de ese año:

12 El profesor de la Universidad de Granada, Eduardo Quesada Dorador publicará en fechas próximas una extensa investigación sobre Joaquín Amigo. 
Compromiso ético, independencia intelectual y ayuda en momentos de crisis

Mi excelente amigo don Manuel Ángeles Ortiz va a París, donde pasará una larga temporada, y desea conocer a usted por ser un fiel devoto de su obra [...] Se trata de un amigo a quien estimo muy de veras y de un artista cuyo real valor tendrá usted ocasión de apreciar. (A.A.V.V.2001: 132)

Manuel Ángeles cambió notablemente su idea del arte y Picasso se mostró muy satisfecho de ese cambio y de los resultados de la obra del artista. Llegaron a ser grandes amigos.

Entre 1932 y 1933, el gobierno de la República, que quería hacer disminuir el control de la iglesia sobre la enseñanza, organizó unos cursillos de formación y convocó plazas de profesores. Manuel Ángeles volvió a España y consiguió un puesto como profesor de dibujo del instituto Maragall de Barcelona, aunque al estallar la guerra fue movilizado. Cuando las tropas franquistas estaban a las puertas de la ciudad condal, en 1939 huyó a través de los Pirineos, pero fue conducido a un campo de refugiados. ${ }^{13}$

El compromiso de Picasso con la República queda claramente de manifiesto en su obra El Guernica, que hizo para el pabellón español en la exposición de París de 1937, o en Sueño y mentira de Franco. Suscribió en varias ocasiones declaraciones en favor de la República, así como participó en diversas asociaciones y exposiciones antifranquistas antes del fin del la Guerra Civil y, tras esta, formó parte del Comité de Ayuda a los Intelectuales Españoles en Francia, comité al que cedió un porcentaje de sus ventas en Estados Unidos. Asimismo, participó en exposiciones destinadas a socorrer económicamente a los niños españoles y fue miembro de la Junta de Cultura Española, presidida por José Bergamín y creada en marzo de 1939 en París por las embajadas española y mejicana. Después de la Guerra, Picasso envió a Renau 1500 francos durante tres meses tras lograr este abandonar del campo de Argèles-sur-mer, y ayudó a salir de los campos y a desplazarse a otros países a muchos españoles. Mercedes Guillén, esposa del escultor Baltasar Lobo, uno de los artistas a quienes en 1939 asistió Picasso económicamente, publicó en 1960, a partir de testimonios directos, la primera obra sobre la llamada Escuela Española de París. En este libro informó sobre el tipo de ayuda prestada por Picasso a los jóvenes artistas recluidos en los campos franceses de refugiados que le escribían pidiéndole incluso material para pintar. (Guillén 1960: 30). En un texto recoge cómo

En la primavera de 1939, a la casa de Picasso [...] llegaban muchos españoles que en aquellos días esperaban la posibilidad de quedarse a trabajar en Francia. La

13 Sobre el papel desempeñado por Picasso en ayuda de los exiliados, ver Cabañas Bravo 2008. 
casa se llenaba de compatriotas que llegaban a ella como a la tabla de salvación, en busca de una solución eficaz, en muchos casos la única que les quedaba. Picasso se desvivía por todos. Oía a uno tras otro, escribía en un trozo de papel o en la libreta más a mano una palabra, un número, un jeroglífico. Otras veces bastaba una mirada a su amigo Sabartés, casi siempre presente, para que éste comprendiera y apuntase una dirección, un nombre. Su intervención era siempre oportuna y justa: a cada uno lo suyo, lo que necesitase. No preguntaba nada -bastaba que fuera un exiliado español-, escuchaba, y encontraba inmediatamente la solución para cada caso. (Guillén 1975: 28-42)

Miguel Cabañas Bravo ha investigado sobre la ayuda prestada por Pablo Picasso a los artistas que llegaron a Francia en 1939 tras la derrota del frente catalán. Entre ellos se cuentan, Antonio Rodríguez Luna, Pedro Flores o Manuel Ángeles Ortiz, junto a otros como Baltasar Lobo, Apel.les Fenosa, socorridos económicamente, Antoni Clavé o Carles Fontseré.

No me resisto a incluir un mensaje que me resulta extremadamente emocionante y que fue escrito por Pablo Picasso en el reverso de un giro dirigido a Manuel Ángeles Ortiz, cuando este se encontraba en el campo de refugiados de Saint Cyprien, al que había llegado huyendo de España, como tantos otros.

Amigo Ortiz aquí le mando mil francos. Su madre y su hija están aquí en París en su taller de la rue Vercingetorix. Cuando llegaron a la frontera me mandaron un telegrama. Yo les mandé mil francos. Ayer fui a verlas y les di sus señas. Nos ocupamos de V. y de los otros haciendo todo lo que podamos para sacarlos de ese infierno. Un abrazo y hasta pronto de su amigo Picasso. Escriba. (Rodrigo 1984: 295) $)^{14}$

Sus gestiones permitirían al pintor abandonar el campo y llegar a París, donde sería recibido en la estación por su benefactor. Manuel Ángeles Ortiz enmarcó ese giro y lo conservó toda su vida, como siempre atesoraría su amistad con Picasso.

Pero ¿qué fue del genial cronista gráfico con el que comenzaba estas líneas? ¿qué fue de Luis Bagaría? Cuando estalló la Guerra Civil, republicano y de fuertes convicciones de izquierdas, marchará a Barcelona a colaborar con el diario La Vanguardia. Fue después a París e hizo ilustraciones para La voz de

14 Pablo Picasso a Manuel Ángeles Ortiz, 1939. El giro en cuestión se reprodujo en 1980 en el catálogo de la exposición homenaje al pintor que organizaron el Ministerio de Cultura y la Dirección General del Patrimonio Artístico en el Auditorio Manuel de Falla y la Fundación Rodríguez-Acosta y transcrito por la misma Antonina Rodrigo, autora del texto del mencionado catálogo, cinco años después (Rodrigo 1984: 295). 
Compromiso ético, independencia intelectual y ayuda en momentos de crisis

Madrid (luego la voz de España, que editaban los exiliados). Ante el avance del ejército nazi, tomó la determinación de viajar a La Habana, donde murió en la miseria en junio de 1940.

No quiero terminar aquí mi relato, que ha tenido como protagonistas a hombres libres, defensores a ultranza de la independencia intelectual, política y moral, sin recoger las palabras de Luis Bagaría en una entrevista (Luján 1930) concedida en El Mañana de Teruel el 27 de mayo de 1930:

No basta saber dibujar. Es necesario tener el corazón a la intemperie. Así el corazón del dibujante pasa a ser el corazón del pueblo. Y sus latidos responden al aire que se respira. De este modo, el dibujante llora cuando llora el pueblo y ríe si el pueblo está gozoso. Cuando le encarecen el ambiente, ese pobre corazón a la intemperie, se asfixia y deja de latir.

\author{
Esperanza Guillén \\ eguillen@ugr.es \\ Departamento de Historia del Arte \\ Facultad de Filosofia y Letras \\ Universidad de Granada \\ 18071 Granada \\ ESPAÑA / SPAIN
}

\title{
Referencias
}

A.A.V.V. 2007. Bagaría en el Sol. Política y humor en la crisis de la Restauración. Madrid: Fundación Cultural Mapfre.

A.A.V.V. 2001. Manuel de Falla en Granada. Granada: Publicaciones del Archivo Manuel de Falla.

Bagaría, L. 1936. Diálogo con García Lorca. - El Sol, 10.06, 5. Lectura en línea 30-92015. Hemeroteca Digital de la Biblioteca Nacional de España.

Cabañas Bravo, M. 2008. Picasso y su ayuda a los artistas españoles de los campos de concentración franceses. - J. Santos, coor., La Guerra Civil Española 1936-1939. Congreso Internacional. Madrid: SECC.1-23. Edición digital.

Elorza, A. 1988. Luis Bagaría. El humor y la política. Barcelona: Anthropos.

Esteban, J. 2009. Luis Bagaría. Caricaturas republicanas. Madrid: Rey Lear.

Gomez Molleda, M. D., ed. 2002. Actas del Congreso Internacional del cincuentenario de Unamuno. Salamanca: Ediciones de la Universidad de Salamanca.

González de Durana, J. 1986. Cartas íntimas. Epistolario entre Miguel de Unamuno y los hermanos Gutiérrez Abascal. Bilbao: Eguzki.

Guillén, E. 2013. Orgullo y dependencia. Cartas de artistas españoles. Jaén: Tinta Blanca. 
GUILLÉN

Guillén, M. 1960. Conversaciones con los artistas españoles de la Escuela de París. Madrid: Taurus.

Guillén, M., 1975. Picasso. Madrid: Siglo XXI.

Luján, G. de. 1930. Las cosas que le ocurrían al gran dibujante Bagaría con el lápiz rojo de la censura. - El Mañana, 27.05, 3. Lectura en línea, 31.03.1917. Biblioteca Virtual de Aragón, http://bibliotecavirtual.aragon.es/bva/i18n/catalogo_imagenes/ grupo.cmd?path=3701087 (31.03.2017).

Macho, V. 1972. Memorias. Madrid: G. del Toro.

Marcos Villalón, E. 2004. Luis Bagaría entre el arte y la política. Madrid: Biblioteca Nueva.

Mata Anaya, J. 2004. Apogeo y silencio de Hermenegildo Lanz. Granada: Diputación.

Manuel Ángeles Ortiz. Exposición homenaje 1980. Auditorio Manuel de Falla y Fundación Rodríguez-Acosta. Madrid: Ministerio de Cultura y Dirección General de Patrimonio Artístico.

Ortega y Gasset, E. 1925. La España Encadenada: La verdad sobre la dictadura. París: Juan Dura.

Ouimette, V. 1982. El destierro de Unamuno y el ataque a la inteligencia. - Cuadernos de la cátedra Miguel de Unamuno, 27, 25-41.

Pompey, F. 1972. Recuerdos de un pintor que escribe. Semblanzas de grandes figuras. Madrid: Artes Gráficas Iberoamericanas.

Quesada Dorador, E. 2001. Imágenes de Manuel de Falla en Granada. - A.A.V.V., Manuel de Falla en Granada. Granada: Archivo Manuel de Falla, 87-154.

Rodrigo, A. 1984. Memoria de Granada: Manuel Ángeles Ortiz. Federico García Lorca. Barcelona: Plaza \& Janés.

Thomas, H. 1961. La Guerra Civil española. Madrid, Ruedo Ibérico.

Titos Martínez, M. 2011. Las actitudes políticas de Manuel de Falla: confianza, desconcierto y prevención. - Cuadernos de Historia Contemporánea, 33, 203-234.

Urrutia, M. M. 1997. Evolución del pensamiento político de Unamuno. Universidad de Deusto.

Urrutia Jordana, A. 2015. La poetización de la política en el Unamuno exiliado. De Fuerteventura a París y Romancero del destierro. Salamanca: Ediciones de la Universidad de Salamanca. 